\title{
GUERREIRO RAMOȘ, A REDUÇÃO SOCIOLÓGICA E O IMAGINÁRIO PÓS-COLONIAL ${ }^{1}$
}

\author{
Fernando de Barros Filgueiras*
}

\begin{abstract}
O aprimoramento recente da sociologia latino-americana caminha no sentido de reforçar e valorizar a produção científica própria. Isso permite consolidar uma autointerpretação de sua realidade social capaz de promover o desenvolvimento das diferentes potencialidades das sociedades latino-americanas. O objetivo deste texto é resgatar as posições práticas e epistemológicas de Alberto Guerreiro Ramos publicadas em diferentes meios e conhecidas como "redução sociológica”. A partir das posiçỗes de Guerreiro Ramos apresentadas no II Congresso Latino Americano de Sociologia, pretende-se relacionar os termos da redução sociológica com o imaginário pós-colonialista, observando proximidades e distanciamentos metodológicos do ofício da sociologia e as inovações proporcionadas pelo autor a partir do conceito de redução sociológica.

PALAVRAS-CHAVE: teoria sociológica, pensamento social brasileiro, epistemologia das ciências sociais, nacionalismo, pós-colonialismo.
\end{abstract}

\section{INTRODUÇÃO}

Do ponto de vista teórico, o pensamento pós-colonial propõe uma mirada crítica sobre os conceitos de Ocidente e modernidade, ressaltando os significados alternativos que culturas subalternas propõem para os conflitos sociais contemporâneos (Spivak, 1994). O pensamento póscolonial procura compreender o modo como se constituem esses significados e o que eles representam para consolidar uma saída própria em relação aos conflitos inerentes às referidas culturas.

De acordo com essa premissa que caracteriza o pensamento pós-colonial, a condição de colônia não se resume a um arranjo político e econômico de opressão e exploração, mas também à construção de uma cultura subalterna,

${ }^{1}$ Agradeço o apoio do Instituto de Pesquisa Econômica e Aplicada (IPEA), que viabilizou a pesquisa realizada sobre o pensamento de Guerreiro Ramos que deu ensejo a este artigo.

* Doutor em Ciência Política. Professor da Universidade Federal de Minas Gerais (UFMG), no Departamento de Ciência Política. Coordenador do Centro de Referência do Interesse Público (CRIP), da mesma universidade.

Av. Antônio Carlos, 6627, sala 4085 Pampulha. Cep: 31270900 - Belo Horizonte - MG - Brasil. ffilgueiras@fafich.ufmg.br em que os valores e as percepções de mundo se alinham aos valores e percepções constituídas pela cultura ocidental. O colonialismo não é apenas um arranjo de exploração econômica. É, também, uma condição de subalternidade da cultura nativa, que tem consequências na construção das identidades. O sujeito colonizado é aquele que, em detrimento de sua cultura nativa, se submete aos valores e percepções constituídas pela cultura moderna.

A condição colonial, portanto, não é apenas uma condição de dominação econômica, mas também a submissão a um padrão de conhecimento dirigido e imposto pela cultura moderna. É nesse sentido que a discussão da condição póscolonial deve tratar, antes de qualquer coisa, das condições epistemológicas em que o conhecimento social é constituído. O discurso moderno da ciência impõe as condições do conhecimento, criando concepções de verdade que não resultam em autonomia, mas reproduzem condições a partir das quais o colonialismo se reproduz e se fortalece (Santos, 2003).

A questão central das teorias pós-coloni- 
ais é ressaltar o papel que as culturas subalternas exercem no conhecimento social e sua importância para a construção da autonomia da sociedade na construção do desenvolvimento. Nesse sentido, valorizam-se essas culturas, ressaltando a importância da solidez dessas identidades. A identidade é importante a partir do momento em que não se justifica que uma cultura possa ser capaz de impor um padrão único de conhecimento. O fundamento do póscolonialismo é que as culturas podem estabelecer diálogo sem haver um padrão de valores e percepções que se imponha a outras culturas.

Esses diálogos culturais têm sido a tônica, no âmbito das ciências sociais, da construção de uma perspectiva crítica de culturas hegemônicas da modernidade. Eles significam a possibilidade de outra via para a questão do desenvolvimento político, social e econômico que se configura pela valorização das identidades. Tendo em vista a discussão sobre as identidades, duas têm sido as possibilidades abertas pela perspectiva pós-colonialista: (1) a constituição do diálogo sul-sul, com o objetivo de possibilitar o desenvolvimento das culturas do sul e a construção de uma aliança contra a hegemonia do ocidente; (2) a reinterpretação e a ressignificação do nacionalismo.

O movimento pós-colonial é apresentado como uma perspectiva pós-moderna. Todavia a primeira utilização do termo e a construção do seu significado surgiram nos movimentos de descolonização dos países do sul, incluindo os países da África e os do oriente, em especial a Índia. Historicamente, os movimentos póscolonialistas surgiram em meados do século XX, no contexto pós-segunda grande guerra e por meio dos movimentos de independência dos países africanos e asiáticos. Dessa maneira, é importante frisar que o pós-colonialismo não constitui um movimento único. Ele deve ser compreendido, por um lado, como valorização diferenciada das culturas nacionais e, de outro, como um movimento de constituição do conhecimento que valorize as culturas locais. Esse conhecimento pós-colonialista do social passa por uma perspectiva interdisciplinar que compreende os parâmetros traçados pela sociologia, pela política, pela economia e pela literatura, compondo um ramo de interpretação e significação da cultura com o objetivo de fortalecer as identidades nacionais e buscar caminhos próprios para o desenvolvimento.

No caso da América Latina, o movimento pós-colonialista foi recebido em comparação com os processos de independência dos países orientais e africanos. É marcante, nos debates fundadores das ciências sociais, a influência que o pensamento latino-americano recebeu do movimento pós-colonial. O movimento pós-colonialista latino-americano surgiu no mesmo contexto de meados do século XX, por influência da discussão sobre o papel do conhecimento nos movimentos nacionalistas. No caso brasileiro, merecem destaque as posições defendidas por Alberto Guerreiro Ramos, as quais podem ser enquadradas como pós-coloniais à medida que valorizam o papel da cultura brasileira na constituição de uma real independência e procura pela constituição de um significado para o nacionalismo brasileiro no contexto do desenvolvimento nacional. Isso fica claro nas teses defendidas por Guerreiro Ramos no II Congresso Latino-Americano de Sociologia, ocorrido em São Paulo e no Rio de Janeiro em 1953.

A partir desse enquadramento, o objetivo deste texto é discutir a tese da redução sociológica e seu papel na constituição de um imaginário pós-colonial no Brasil, com especial enfoque na questão do desenvolvimento nacional. Mostraremos como a tese da redução sociológica de Guerreiro Ramos resultou em uma concepção instrumental de desenvolvimento que visa a satisfazer uma concepção pós-colonial da cultura brasileira. Também mostraremos as possibilidades da crítica aberta por Guerreiro Ramos ao próprio nacionalismo brasileiro, com o objetivo de ressaltar suas particularidades frente à sociologia brasileira. 


\section{A REDUÇÃO SOCIOLÓGICA COMO MARCO DO EXISTENCIALISMO BRASILEIRO}

É mais do que conhecido o fato de que Guerreiro Ramos buscava para a sociologia um sentido prático, que congregasse, ao mesmo tempo, os avanços da ciência social e os problemas práticos da sociedade brasileira no que diz respeito às condições do nosso atraso. Também é mais do que conhecido o fato de que a sociologia defendida por Guerreiro Ramos tem o caráter de engajamento nas questões sociais, mesmo que isso significasse, a seu juízo, o sacrifício da objetividade da ciência. A sociologia deveria ter, de acordo com o autor, o tom de uma ciência interpretativa (Oliveira, 1995).

Sua militância no Teatro da Experimentação Negra (TEN) exerceu forte influência sobre o tipo de conhecimento necessário para a constituição da autonomia, seja de estratos sociais específicos, como o caso dos negros, seja da sociedade brasileira em seu conjunto. O fato é que Guerreiro Ramos procurou defender uma sociologia engajada, com a preocupação constante de influenciar e participar da vida política nacional. No caso de sua sociologia sobre o negro brasileiro, influenciada pelas posições de Abdias do Nascimento, ele propõe que ela fosse uma espécie de voz do próprio negro. Ou seja, a sociologia da questão racial no Brasil deveria ser feita pelo próprio negro, o qual tomaria consciência de sua própria negritude e assumiria uma posição militante capaz de influenciar a agenda política. A posição dessa sociologia do engajamento do negro, fortemente influenciada por Franz Fanon, quer romper o estatuto colonial do racismo para difundir uma perspectiva de autonomia, constituída, sobretudo, pela ação política. Contra as posições de Gilberto Freyre (2000) e de Arthur Ramos (2002), que tendiam a olhar o negro como um objeto folclórico, Guerreiro defendia, nessa posição de uma sociologia engajada, o rompimento da condição de cultura colonizada da negritude, difundido e apoiando os valores que são inerentes às suas tradições (Ramos, 1950; Maio, 1997).
Mas é importante frisar que Guerreiro não defendia o endosso entusiástico das "sobrevivências africanas". Para ele, o erro de sociólogos e antropólogos, quando discutem a questão do negro do Brasil, é tratá-los como objeto exótico, desalinhado e estrangeiro em relação à própria cultura nacional. Em sua disputa com Costa Pinto, Guerreiro Ramos afirmava que o preconceito em relação ao negro, no Brasil, não era de raça, mas de cor, o que significaria o fato de que, ao contrário de outras sociedades, o preconceito não se constitui, no Brasil, por linhas de castas. ${ }^{2} \mathrm{O}$ fato de o preconceito contra o negro não se constituir por linhas de castas é que permite que ele possa ser integrado no conjunto da Nação. Os estudos sobre o negro no Brasil seriam alienados, de acordo com Guerreiro, porque se espelhavam nos parâmetros sociológicos das realidades sociais europeia e norte-americana. A saída para o negro, de acordo com Guerreiro Ramos, seria ascender socioculturalmente por meio da luta de classes, constituindo, por conseguinte, um processo de cooperação que lhe permita participar da cultura nacional (Maio, 1997). O mesmo se pode dizer de outro ramo de conhecimento sociológico ao qual Guerreiro Ramos se dedicou. O tema da administração pública e das organizações do Estado deveria romper com os projetos de modernização desenvolvidos pela cultura ocidental e buscar uma rota própria de constituição das instituições políticas e burocráticas. Guerreiro Ramos foi um dos responsáveis por introduzir a sociologia de Weber no Brasil, quando de sua atuação no Departamento de Administração do Serviço Público

${ }^{2}$ A sociologia sobre o tema das raças de Costa Pinto circunscreve-se no projeto da UNESCO, voltado para a construção de um conceito científico de raça que pudesse se contrapor às matrizes racialistas. De acordo com Costa Pinto, a questão do negro no Brasil deve ser compreendida na dimensão das classes, observando-se, sobretudo, a posição do negro-proletário. Ademais, é fundamental observar o conflito intra-raça, que promove a ascensão isolada de negros e mulatos, constituindo um quadro de tensão social que envolve uma elite negra de classe média, que enfrenta a barreira representada pelos valores tradicionais do branco, o qual tenta colocar, a todo instante, o negro "em seu lugar". E nesse sentido que a questão racial assemelhar-se-ia a um domínio de castas, em que o problema fundamental é o da hierarquia social estabelecida em torno de valores. A esse respeito, conferir Maio (1997). 
(DASP). Como funcionário do DASP e, mais tarde, assessor de Getúlio Vargas, Guerreiro Ramos se dedicou a diferentes pesquisas empíricas e à introdução e discussão de diferentes matrizes teóricas da sociologia das organizações. Para ele, a organização do serviço público deveria ter uma base científica, voltada para temas práticos, tais como a mortalidade infantil, o orçamento familiar, o processo de industrialização e urbanização, as transformações nos padrões de consumo da sociedade. Esses temas, aos quais Guerreiro se dedicou, quando funcionário do DASP, firmaram o pressuposto de que, para ele, o conhecimento sociológico é, antes de qualquer coisa, um conhecimento prático, voltado para os problemas sociais contemporâneos. O que essa sociologia engajada jamais poderia perder, segundo ele, é o caráter de promoção existencial da autonomia da vida social. Como intelectual, Guerreiro Ramos procurou constituir essa sociologia prática, mas seu trabalho foi realizado de forma quase isolada, sem um contexto institucionalizado que lhe desse apoio e sustentação. A exceção é o período em que ele atuou no Instituto Superior de Estudos Brasileiros (ISEB) e depois quando ajudou a fundar a Escola Brasileira de Administração Pública da Fundação Getúlio Vargas (Schwartzman, 1983).

Essa posição de uma "sociologia em man- gico. Para Florestan, não importavam as particularidades históricas e sociais de uma sociedade para que o trabalho científico fosse possível. A sociologia é, para ele, uma ciência positiva, o que demanda uma especialização voltada para a construção do conhecimento, cujo trabalho é feito por acadêmicos treinados nas doutrinas e atividades inerentes ao trabalho empírico. As ciências sociais brasileiras, de acordo com Fernandes, deveriam romper com o padrão ensaístico que então a dominava, institucionalizando o ofício de sociólogo em torno de padrões científicos universais (Fernandes, 1977). Para Guerreiro Ramos, por outro lado, o trabalho da sociologia no Brasil deveria buscar uma perspectiva de afloração da consciência. A tarefa primordial da sociologia no Brasil, observando as condições histórico-sociais da Nação, seria a busca de uma condição existencial da sociedade, fazendo-a tomar consciência de suas condições e possibilitando-a rever suas trajetórias e fins (Ramos, 1996).

Em função dessa controvérsia, Guerreiro Ramos procurou organizar suas teses sobre a epistemologia das ciências sociais no Brasil em A redução sociológica, originalmente publicado em 1965. Para o autor:

A redução sociológica é um método destinado a
habilitar o estudioso a praticar a transposição de
conhecimentos e de experiências de uma pers-
pectiva para outra. O que a inspira é a consciên-
cia sistemática de que existe uma perspectiva
brasileira. Toda cultura nacional é uma perspec-
tiva particular. Eis porque a redução sociológica
é, apenas, modalidade restrita de atitude geral
que deve ser assumida por qualquer cultura em
processo de fundação (Ramos, 1996, p. 42).

A influência que o pensamento pós-colonial de Franz Fanon e de Balandier exerceu em Guerreiro Ramos está no fato de que a atividade sociológica configura-se, epistemologicamente, no que ele está nomeando como perspectiva. Uma perspectiva, para Guerreiro, é o modo segundo o qual se constitui um tipo de olhar diferenciado sobre um objeto de estudo, olhar que se conforma e ganha substrato normativo por meio de uma cultura que o insere em um conjunto de valores e de percepções de mundo. A sociologia 
é um tipo de atividade hermenêutica, em que as percepções acerca do próprio mundo social configuram os problemas e o modo de abordar determinada realidade social. Por influência da filosofia de Husserl, a perspectiva é um tipo de abordagem do mundo social estipulada pela cultura.

De acordo com essa ideia de perspectiva, três elementos precisam ser destacados em relação à tarefa da redução sociológica, de acordo com Guerreiro Ramos: (1) ela é um tipo de conhecimento fundacional, inspirado na busca das condições ontológicas e existenciais da cultura brasileira; (2) a redução sociológica ressalta a necessidade de se compreenderem as condições críticas para a ciência nacional; (3) as condições dessa consciência crítica suscitam a existência de uma cultura particular, e é essa cultura o objeto primordial da sociologia brasileira. Por essa perspectiva, não cabe, segundo Guerreiro, a existência de uma sociologia institucionalizada se ela não se der conta do fato nacional brasileiro e de seus problemas concretos. A tarefa da redução sociológica, frente a um padrão institucionalizado de conhecimento sociológico então em ascensão no Brasil, seria descortinar os problemas reais da sociedade brasileira, focados nos valores e percepções definidos por nossa identidade nacional. Não basta, segundo o autor, importar formas de conhecimento exteriores à nossa cultura, pois o resultado é reproduzir uma condição subalterna e alienada que contraria a própria existência da sociedade brasileira. Se a sociologia é um tipo de conhecimento prático, cabe a ela buscar as bases interpretativas da cultura, com o condão de focar e rever os problemas sociais dela derivados.

A obra de Guerreiro Ramos também recebeu forte influência do existencialismo de Sartre e da ontologia de Heidegger. Se o objetivo da sociologia é descortinar as condições existenciais da sociedade brasileira, atesta Guerreiro Ramos que todas as questões e perguntas suscitadas pela atividade sociológica devem se dirigir ao que ele nomeou como fato nacional brasileiro. As condições existenciais que Guerreiro pro- curou compreender dizem respeito à configuração da identidade nacional no Brasil. O fato nacional brasileiro diz respeito ao fato de o Brasil ter deixado de ser um povo "natural" para se tornar um povo "histórico". As condições do desenvolvimento acelerado na era Vargas propiciaram o aflorar dessa consciência crítica que deveria ser organizada e refletida pela sociologia. As condições do desenvolvimento brasileiro, que, segundo o autor, se expressam pela industrialização, pela urbanização e pela mudança nos padrões de consumo, com a inclusão do meio popular, suscitaram o estágio de uma consciência crítica do Brasil sobre si mesmo. O Brasil, finalmente, havia chegado à sua condição histórica, rompendo os padrões impostos pelo estatuto colonial. E, pelo fato de ter alcançado a sua condição histórica, é que o conhecimento sociológico se torna possível e necessário.

Observando o movimento de reação ao colonialismo no mundo afroasiático, Guerreiro Ramos aponta para o fato de que a redução sociológica é uma tarefa de construção de um conhecimento em torno de uma perspectiva da cultura nacional. O mesmo movimento que se verificava nas conferências de Badoeng (1955), do Cairo (1957) e de Acra e Tânger (1958), o autor verificava no Brasil, tendo em vista ações que se constituíam por normas derivadas de projetos autônomos de existência. A redução sociológica, portanto, é um movimento pós-colonial de busca de um conhecimento existencial próprio, que não nega os avanços da ciência, mas não reproduz os termos hegemônicos de seu discurso. A redução sociológica é, sobretudo, uma atitude consciente e crítica, cujo conteúdo não é parcial, mas de reivindicação universal de reconhecimento da própria existência. É nesse sentido que não é possível compreender a sociologia de Guerreiro Ramos sem compreender suas teses sobre o nacionalismo.

Se a redução sociológica significa um aflorar da consciência crítica de uma sociedade, as identidades nacionais são fundamentais como substrato normativo de uma sociologia engajada. 
É importante frisar que, para Guerreiro Ramos, o nacionalismo não é um movimento político baseado em heranças raciais ou fundamentalistas. O nacionalismo, para ele, é uma experiência de ação comunitária, fundada em valores e fins capazes de instituir, por meio do poder, as possibilidades contidas em uma etapa social determinada. Em primeiro lugar, é necessário observar o que Guerreiro entende por poder. Seguindo o conceito weberiano, poder é ".... a oportunidade que possui um indivíduo, ou um grupo, de impor a sua vontade na ação comum, mesmo contra a resistência de outros que dela participam" (Weber apud Ramos, 1957, p.18). O poder, para Guerreiro, é um ingrediente inseparável de toda sociedade. O autor absorve esse conceito weberiano de poder, observando o fato de que a vontade constitui o elemento primordial da ação comunitária. Seguindo a sociologia weberiana, se a ação comunitária estabelece os valores fundamentais da ação política, é necessário configurar o conceito de poder em torno de situações históricas dadas. É nesse sentido que, para Guerreiro Ramos, o conceito de poder deve ser seguido de um adjetivo. Nesse caso, o termo poder, para ele, deve ser seguido da característica nacional, observando-se, nesse caso, o modo como a direção política de uma sociedade é exercida. A característica nacional diz respeito ao olhar que a sociologia nacionalista deveria lançar sobre o corpo político, tomando as posições das classes dominantes e das classes dirigentes como objeto fundamental da interpretação política. Sendo o nacionalismo uma experiência social que funda os valores básicos da ação comunitária, o poder deve ser seguido da expressão nacional.

É o poder nacional o conjunto de todos os grupos e indivíduos dirigentes que desempenham papel ativo na organização de um país; de todos os elementos políticos por excelência que concentram em suas mãos a direção econômico-social, o poder militar e as funções administrativas. (Ramos, 1957, p.11)

O nacionalismo, nesse sentido, não é a expressão exótica de uma orientação fundamentalista, mas é o conjunto dos valores e percepções esti- pulados em uma cultura que delineia a direção do poder político. A condição moderna do poder político exige que a vontade seja estipulada por uma razão normativa de fundo. A condição nacional, nesse sentido, é o aflorar de uma consciência crítica, capaz de configurar a vontade por meio de uma existência autônoma de um povo. O nacionalismo, portanto, é um substrato normativo capaz de informar a vontade coletiva por meio da ação comunitária e, dessa forma, conformar a ação social por meio da atividade política (1957). O nacionalismo, ademais, é a ruptura com a situação de dependência colonial, constituindo as premissas fundamentais para conduzir o processo emancipatório de um país (Ramos, 1960; Souza, 2009).

O caso brasileiro, nesse sentido, revela o fato de que o poder nacional emergiu com o processo de desenvolvimento. A independência do Brasil, em 1822, segundo Guerreiro Ramos, não proporcionou a emancipação social. O processo de independência apenas estabeleceu uma forma nacional para a sociedade, sem a presença do substrato normativo das identidades. O Brasil Império e a República Velha seriam o domínio privado de fazendeiros, que se institucionalizava na forma de oligarquias mantidas em torno de compromissos políticos. "O que sociologicamente é relevante, porém, é assinalar que, durante o período de dominação dos fazendeiros, o Brasil foi um país sem povo" (1957, p.14). A independência instituiu uma forma nacional, sem um conteúdo de valores capaz de assegurar a existência de uma identidade e de uma cultura nacional. A ruptura só ocorreria a partir da industrialização e urbanização do Brasil, fazendo com que os titulares do poder, os proprietários de terras, perdessem suas posições dominantes. Contudo, não perderam sua condição dirigente.

A modernização brasileira criou um hiato, segundo Guerreiro, entre as classes dominantes e as classes dirigentes. Esse desencontro seria o principal entrave à emergência do poder nacional no Brasil, uma vez que não propiciaria o fato de a vontade geral poder condicionar a ação 
política. O Brasil da era Vargas seria o Brasil do desencontro entre as classes dominantes e as classes dirigentes. O problema principal, de acordo com o autor, é o fato de que o desenvolvimento brasileiro segue um modelo de complementaridade. Ele não permite o aflorar de uma cultura capaz de romper com a dependência colonial. Uma vez que a classe dirigente alinha-se a todo o atraso brasileiro, originado do estatuto colonial, cria-se um processo complementar de desenvolvimento que reproduz as amarras de uma cultura dependente. $\mathrm{O}$ desenvolvimento, sem o substrato normativo do nacionalismo, terminaria por reproduzir as condições de dependência colonial. O desenvolvimento seria uma espécie de fuga para a frente, sem proporcionar um processo sólido de emancipação social. O nacionalismo no Brasil, segundo Guerreiro Ramos, seria o fator de ruptura, dependente da posição que as classes dominantes exerceriam no processo de afloramento de uma cultura pós-colonial. O fundamental é romper com a complementaridade do desenvolvimento, pois:

Jamais poderemos levar a bom termo o nosso processo de emancipação, se as instâncias do poder, em suas mais diversas modalidades, forem apenas receptivas ao que se contém de possibilidade material nesse processo, e não sentirem a exigência ética nele incluída, isto é, o seu conteúdo de valor. Na medida em que tais instâncias de poder pautarem sua ação em critérios correspondentes ao que aqui estamos chamando de complementaridade, estarão não só embaraçando o processo de emancipação, como desvirtuando-o, degradando-o (Ramos, 1957, p.30).

O surgimento de uma mentalidade nacional (ou pós-colonial) no Brasil dependeria de uma modificação das bases interpretativas da sociedade, capazes de romper com o processo complementar do desenvolvimento. A redução sociológica, nesses termos, serviria para a construção de bases interpretativas do Brasil solidificadas em uma mentalidade nacional. Não se pode compreender, por conseguinte, o problema epistemológico da sociologia, lançado por Guerreiro Ramos, sem a compreensão de suas teses sobre o nacionalismo.
Como a redução sociológica é a tarefa mediante a qual se descobrem os pressupostos referenciais dos objetos e fatos da realidade social (Ramos, 1996, p.71), ela não é ditada pelo imperativo do conhecimento pelo conhecimento, mas por sua atividade prática, balizada nas necessidades reais da comunidade e no projeto de sua existência histórica. A sociologia é fundamental ao afloramento de uma mentalidade nacional à medida que ela sirva à busca das experiências existenciais de um povo. Mas, antes de qualquer coisa, ela exige, segundo Guerreiro Ramos, uma posição metódica e científica. A redução sociológica é um processo de conhecimento. $\mathrm{O}$ autor postula um conjunto de enunciados que configuram esse processo, conforme é posto a seguir:

\section{- A redução sociológica é uma atitude metódica}

Com isso, o autor quer dizer que o conhecimento sobre a sociedade exige a obediência a regras que se pautem pelo esforço de depurar o objeto de estudo, com o objetivo de formulação exaustiva e radical do seu significado. A atitude metódica não é uma atitude espontânea. Ela pretende dar conta dos significados mais profundos da realidade social, indo além dos aspectos externos dos fenômenos sociais. A atitude metódica não trata de afirmar ou aceitar os aspectos da realidade social, mas invertê-los com o fim de fazer do conhecimento uma ferramenta para a emancipação social.

\section{- A redução sociológica não admite a existência, na realidade social, de objetos sem pressupostos}

Para Guerreiro Ramos, seguindo a sociologia weberiana, a realidade social é sistemática e representa um conjunto de fatos que guardam conexões entre si. A realidade social é dotada de sentido, e são suas conexões de sentido que estabelecem as significações sociais. Os pressupostos dizem respeito ao processo de valoração social que estabelece o significado dos objetos de estudo do sociólogo. Logo, é fundamental ao pro- 
cesso de conhecimento, por meio da redução sociológica, absorver essas valorações com o objetivo de compreender melhor os vínculos que os fenômenos sociais guardam entre si.

\section{- Aredução sociológica postula a noção de mundo}

Seguindo a filosofia de Husserl, a redução sociológica deve dar conta do fato de que a consciência ocorre à luz da reciprocidade de perspectivas. A consciência e os objetos relacionados à realidade social são reciprocamente relacionados, fazendo com que a primeira seja, por definição, intencional e estruturalmente referida aos objetos. "O mundo que conhecemos e em que agimos é o âmbito em que os indivíduos e os objetos se encontram numa infinita e complicada trama de referências." (Ramos, 1996, p.72). A noção de mundo estipula, portanto, que é fundamental à redução sociológica buscar os elementos referenciais da cultura para estipular seus fins. A atividade interpretativa proporcionada pela sociologia deve dar conta dessa noção de mundo, em que os objetos do conhecimento não estão dissociados do sujeito que procura interpretá-los. Nesse sentido, o próximo postulado suscita a ideia de que o essencial para a redução sociológica é o fato de ela trabalhar com perspectivas.

\section{- A redução sociológica é perspectivista}

Guerreiro Ramos parte da premissa de que a perspectiva segundo a qual os objetos são tomados os constitui. Dessa maneira, o autor estipula que o objeto de estudo não pode estar desligado de seu contexto. A perspectiva é informada, sobretudo, pela cultura, a qual estabelece o conteúdo de sentido definido para o objeto de estudo. Se a sociologia é perspectivista, ela é uma ciência que se insere nos suportes coletivos da realidade social.

\section{- Os suportes para a redução sociológica são coletivos e não individuais}

O trabalho do sociólogo é inserido na sociedade em que ele vive, criando situações que limitam sua margem de especulação. A sociologia, nas palavras de Guerreiro, é um conhecimento operativo e não especulativo, uma vez que seus suportes são coletivos. A sociologia só é possível em uma sociedade que assuma sua autoconsciência como processo coletivo. Isso explica o fato de a sociologia só ter sido possível com a modernidade. A sociologia fundamenta-se em uma lógica imanente à existência da sociedade.

\section{- A redução sociológica é um procedimento crí- tico-assimilativo da experiência estrangeira}

Pelo fato de os suportes da redução sociológica existirem em torno da autoconsciência das sociedades e em torno do fato nacional que a explica, isso não significa que ela deva prescindir dos avanços proporcionados pela ciência e de teorias constituídas em outros países. A ciência, para Guerreiro Ramos, tem uma aspiração universal e diz respeito a problemas que podem vir a afetar diferentes sociedades. Mas o fato de a ciência ter uma pretensão universal não elimina o fato de ela ser mediatizada pelo local, pelo regional ou pelo nacional. A redução sociológica não se opõe à transplantação de conceitos e categorias fundamentais ao conhecimento sociológico, mas exige que eles sejam submetidos a critérios de seletividade. Conceitos e categorias importados devem ser reinterpretados pela cultura nacional, de forma a adequá-los ao seu conteúdo de sentido.

\section{- Embora os suportes coletivos da redução so- ciológica sejam vivências populares, ela é uma atitude altamente elaborada}

A atitude redutora, como nomeia Guerreiro Ramos, não é uma modalidade de impressionismo com relação às vivências popu- 
lares. A atitude redutora precisa ser justificada e baseada em esforços elaborados de reflexão, mostrando as razões pelas quais se fundamenta. A redução sociológica é, antes de tudo, um método para o conhecimento do social, que deve ser autorreferido à cultura que o cerca.

Tendo em vista esses sete postulados traçados por Guerreiro Ramos, a redução sociológica se fundamenta em quatro leis que organizam o trabalho do sociólogo:

a) a lei do comprometimento;

b) a lei do caráter subsidiário da produção científica estrangeira;

c) a lei da universalidade dos enunciados gerais da ciência;

d) a lei das fases.

O caráter de lei significa que a redução sociológica só é possível por essa mirada crítica da posição do sociólogo frente às questões que cercam a comunidade. A lei do comprometimento procura incitar o conhecimento do social aos objetivos derivados da cultura nacional. A sociologia engajada de Guerreiro Ramos exige que “... nos países periféricos, a ideia e a prática da redução sociológica somente podem ocorrer ao cientista social que tenha adotado sistematicamente uma posição de engajamento ou de compromisso consciente com o seu contexto." (Ramos, 1996, p.105). A posição engajada corresponde ao fato de que cabe à redução sociológica a busca dos significados existenciais da comunidade. Essa concepção dista de um endosso entusiástico das heranças históricas ou dos traços exóticos da cultura. A posição epistemológica de Guerreiro Ramos a respeito da redução sociológica é coerente com a sua posição sobre as heranças africanas e a negritude brasileira. $\mathrm{O}$ comprometimento não é a aprovação entusiástica da cultura nacional, mas a imersão sistemática do cientista social no ponto de vista da sua própria comunidade. Dessa forma, o comprometimento, como apontamos nas linhas anteriores, é coerente com a ideia de que a nação é o conjunto dos valores e percepções que uma comunidade faz sobre si mesma. Por esse motivo, a redução sociológica se cerca de uma concepção pós-colonial que quer afirmar a identidade nacional como fundamental para a consolidação da consciência crítica, a qual, por sua vez, possibilita o tipo de conhecimento constituído pela sociologia.

A posição nacionalista de Guerreiro Ramos, nesse sentido, não é contraditória em relação aos objetivos da redução sociológica. O conhecimento produzido no estrangeiro é fundamental para o avanço universal da ciência e para a interpretação crítica que as sociedades podem fazer sobre si mesmas. Por essa razão é que a produção científica estrangeira tem um caráter subsidiário. O nacionalismo de Guerreiro Ramos circunscreve-se na ideia de que as identidades estão inscritas em valores e percepções de mundo que se conformam sob a forma de uma nação, estabelecendo o caráter intencional e prático do conhecimento sobre o social. Transplantar conceitos e categorias desenvolvidos em outras comunidades sem reduzi-los corresponde a utilizálos envolvidos pela intencionalidade de que são portadores. A utilização de produção científica estrangeira é fundamental para a elaboração teórica, de acordo com Guerreiro Ramos, mas ela deve ser condicionada por fatores particulares da sociedade em que vive (1996, p.115).

Com respeito à lei da universalidade, ele prescreve que a "redução sociológica só admite a universalidade da ciência tão somente no domínio dos enunciados gerais." (1996, p.123). A ciência não deve ser feita imbuída de jacobinismo, porquanto representa, para Guerreiro, a conquista do esforço universal dos cientistas. No que diz respeito a essa terceira lei, o autor indaga por que os esforços para a construção de uma sociologia nacional no Brasil não seriam profícuos. Uma sociologia nacional não postula que a sociologia varie de nação para nação, mas que o contexto e a cultura nos quais o conhecimento social é construído importam. O que explica o insucesso de uma sociologia nacional no Brasil, segundo Guerreiro Ramos, é a situação colonial. A situação colonial postula que o Brasil viveria uma essência alienada, em que a mentalidade 
dos analistas seria condicionada por fatores exclusivamente externos. A universalidade da ciência está na produção de enunciados gerais, que podem ser apropriados pelo cientista social a qualquer momento. Contudo, essa apropriação ocorre em um contexto e, por conseguinte, deve estar imbuída de uma intencionalidade que é informada pelos valores e percepções constituídas por uma cultura nacional. No que diz respeito à lei da universalidade dos enunciados gerais da ciência, Guerreiro Ramos retira qualquer possibilidade, ao contrário de Florestan Fernandes, de que a sociologia deva ser concebida como uma ciência positiva, realizada exclusivamente por acadêmicos.

Por fim, a lei das fases postula que à “[...] luz da redução sociológica, a razão dos problemas de uma sociedade particular é sempre dada pela fase em que tal sociedade se encontra." (Ramos, 1996, p.129). Ou seja, existe uma razão histórica que conforma e estabelece as fases em que os problemas relativos à sociedade se configuram. A ideia de fase não corresponde à existência de um pensamento linear em termos de causa e efeito, mas à compreensão de momentos históricos que formam os problemas centrais com os quais as sociedades se debatem.

Guerreiro Ramos teve a ousadia crítica de formular uma filosofia do conhecimento para atribuir o caráter nacional à sociologia brasileira. Sua sociologia em "mangas de camisa", fortemente influenciada por uma razão póscolonialista, não nega a universalidade do conhecimento sociológico, $\mathrm{C} 0 \mathrm{~m} 0$ conhecimento científico. Porém não admite que a atividade dessa sociologia esteja imbuída de uma mentalidade colonial. O caráter das leis da redução sociológica não é o caráter de leis universais da epistemologia, mas o condicionamento, ao mesmo tempo, de uma mentalidade pós-colonial da comunidade científica brasileira, capaz de inseri-la na comunidade universal da ciência. A manutenção de uma mentalidade colonial na sociologia brasileira, com a institucionalização acrítica dos termos da ciência, jamais a inseriria na co- munidade. Além disso, jamais permitiria quebrar o eixo de complementaridade que caracterizou o desenvolvimento brasileiro até então. A sociologia nacional no Brasil, seguindo a lei do comprometimento, deve buscar a consolidação de um imaginário pós-colonial capaz de estabelecer critérios adequados para a avaliação do desenvolvimento e superar o caráter complementar que o cerca.

\section{O DESENVOLVIMENTO BRASILEIRO A PARTIR DA ATIVIDADE DE REDUÇÃO SOCIO- LÓGICA}

A redução sociológica é um método para as ciências sociais brasileiras, o qual está preocupado em estabelecer um conjunto de regras necessárias para a construção do conhecimento social. As leis da redução sociológica estão voltadas para evitar os problemas relacionados ao anacronismo de conceitos e teorias, a falta de retificação dessas teorias em relação ao contexto que pretende ser compreendido e uma interpretação correta do problema do desenvolvimento brasileiro. A atuação de Guerreiro Ramos no ISEB e no DASP, bem como sua atuação na esfera política proporcionaram as bases práticas para o tratamento dispensado ao problema do desenvolvimento.

A abordagem de Guerreiro Ramos sobre o desenvolvimento nacional brasileiro deve ser compreendida, na coerência de sua obra, como o ato de colocar a redução sociológica em prática (Souza, 2009). Nesse sentido, sua concepção de desenvolvimento deve vir seguida do adjetivo nacional, porquanto ela mobiliza as diferentes teorias e concepções relacionadas ao processo de modernização de maneira crítica e comprometida com os problemas brasileiros. A concepção de Guerreiro Ramos sobre o desenvolvimento nacional brasileiro é crítica à perspectiva segundo a qual o desenvolvimento econômico promoveria o desenvolvimento social. Para ele, o desenvolvimento econômico de nada adianta se não for vinculado às bases existenciais da cultura 
brasileira. Sem isso, as ciências sociais produzem uma falsa compreensão do desenvolvimento, reproduzindo as condições de um subdesenvolvimento atrelado a uma mentalidade colonizada.

Essa crítica às perspectivas do desenvolvimento brasileiro traçada por Guerreiro Ramos dirige-se aos cientistas sociais que elaboram critérios comparativos de desenvolvimento, tomando como base conceitos e categorias derivados do pensamento hegemônico europeu e norteamericano. Sem o processo de redução sociológica, os critérios comparativos adotados para a compreensão do desenvolvimento brasileiro não permitem distinguir suas causas e os seus resultados (Ramos, 1996, p.144). Para Guerreiro Ramos, “[...] o desenvolvimento é uma promoção mediante a qual as regiões e nações passam de uma estrutura a outra superior" (1996, p.140). O autor aborda esta questão como um problema estrutural das sociedades, tendo em vista uma sociologia assentada em traços existencialistas marcados pelo conceito de nação. É primordial a esta sociologia que o problema estrutural do desenvolvimento seja enquadrado na matriz de problemas, perspectivas e valores balizados na cultura de fundo. A sociologia nacional brasileira, tendo em vista os conceitos centrais da redução sociológica, deve buscar um critério de desenvolvimento adequado e informado pela cultura nacional. Nenhuma estratégia de desenvolvimento é possível apenas pelo crescimento quantitativo de instituições, quadros e recursos. É necessário que uma estratégia de desenvolvimento seja adequada ao plano estrutural das normas sociais que são informadas pela cultura nacional. Nesse sentido, é fundamental que uma perspectiva nacional de desenvolvimento dê conta de um ponto de vista estratégico. A promoção do desenvolvimento é, segundo Guerreiro, um ato político, e, como tal, exige a participação da sociedade na conformação dos objetivos e valores inerentes à sua fundação (Ramos, 1960).

Guerreiro Ramos compreende por estratégia não uma concepção instrumental de meios e fins, mas a definição de um horizonte de pos- sibilidades que se abrem em confrontação com a cultura de massas. A premissa do problema do desenvolvimento em Guerreiro Ramos é que a concepção do desenvolvimento deve ocorrer a partir dos parâmetros de redução sociológica que implicam o comprometimento do cientista social com o seu contexto, o trabalho metódico e a apropriação de conceitos e categorias de forma subsidiária. O desenvolvimento brasileiro, segundo ele, exigiria um processo de modernização da sociedade, aberto aos valores e percepções constituídas na cultura de massas. No caso brasileiro, o desenvolvimentismo da década de 1950 e 1960 proporcionou mudanças no cenário político, econômico e social brasileiro. Porém carecia, ainda, de uma perspectiva crítica capaz de solidificá-lo no plano dos valores.

Para os objetivos desse texto, é fundamental perceber o modo como a sociologia de Guerreiro Ramos, tendo em vista o método da redução sociológica, é influenciado por uma concepção pós-colonial, bem como essa concepção influencia uma perspectiva de desenvolvimento específica na obra do autor, capaz de enquadrar os objetivos estratégicos da mudança social no quadro de valores e percepções definidos na cultura brasileira. Para tanto, é interessante observar a crítica de Guerreiro em relação às teorias da modernização e a crítica do autor ao formalismo brasileiro.

A concepção de desenvolvimento de Guerreiro Ramos é construída em torno de um trabalho de forte revisão da literatura sobre modernização, administração pública e desenvolvimento econômico. Em Administração e estratégia do desenvolvimento, o autor coloca em revisão os conceitos de burocracia, ação administrativa e modernização para buscar uma concepção adequada do desenvolvimento brasileiro. Traçar uma estratégia de desenvolvimento no Brasil significa aplicar os parâmetros metodológicos da redução sociológica para compreender o melhor caminho da mudança social.

Em primeiro lugar, merece destaque a crítica do autor às teorias da modernização. Para 
Guerreiro Ramos, a mudança social deve ser um processo consciente, tendo em vista a mudança de etapas da estrutura social para compor um processo não-tautológico de evolução institucional. $\mathrm{O}$ autor, apoiado nas sociologias de Eisenstadt e de Don Martindale, afirma que a modernização não obedece a um conjunto de pré-requisitos necessários à configuração de uma sociedade dita moderna. As teorias da modernização erram e promovem tautologias ao procurar por pré-requisitos da mudança social que sejam aplicáveis universalmente. A análise comparativa dos processos de mudança social deve constituir um sistema de conceitos generalizados, capaz de possibilitar a comparação sistemática de diferentes sociedades e definir rotas de modernização e, ao mesmo tempo, distinguir fenômenos particulares da mudança (Souza, 2009).

Na visão do autor, quando o processo de desenvolvimento é analisado pelo olhar de prérequisitos estruturais e funcionais estabelecidos em realidades sociais distintas e ditadas pela experiência dos países do centro do capitalismo, políticos e administradores dos países periféricos são tentados a adotar soluções hipercorretas para os problemas reais dessas nações. Ao invés de buscar soluções hipercorretas, que reproduzem os caminhos adotados pelos países do centro do capitalismo, os países da periferia devem buscar soluções adequadas, as quais necessitam de um ponto de vista estratégico (Ramos, 1966). A estratégia administrativa deve estar voltada para a busca de soluções adequadas ao quadro histórico-cultural da nação, com o objetivo de superar os problemas práticos que se apresentam ao Estado. O Estado é propulsor do desenvolvimento, segundo Guerreiro Ramos, e sua administração deve adotar essa perspectiva estratégica que exige, por sua vez, um processo de redução sociológica (Souza, 2009).

Para Guerreiro Ramos, o principal entrave ao desenvolvimento brasileiro seria o formalismo presente na administração do Estado, o que acarreta o fato de, mesmo com os ganhos do desenvolvimento econômico, não haver uma mudan- ça nos valores da sociedade capaz de encaminhála para a modernidade. $\mathrm{O}$ formalismo, segundo Guerreiro, "[...] é a discrepância entre a conduta concreta e a norma prescrita que se supõe regulála” (Ramos, 1966, p.333). O formalismo é típico de sociedades prismáticas, as quais apresentam alto grau de heterogeneidade, uma vez que nelas coexistem o tradicional e o moderno, o velho e o novo, o atrasado e o avançado. Sociedades prismáticas, segundo o autor, é uma sociedade necessariamente dual e ambivalente, cuja prática convencional é estipular processos de superposição de estruturas que assume a dualidade como marca fundamental das práticas sociais. O formalismo é a discrepância entre o formal e o efetivo, fazendo com que o conhecimento objetivo sobre a realidade institucional desse tipo de sociedade jamais possa ser consolidado a partir de suas estruturas normativas e legais.

O formalismo é típico de sociedades que se estruturam em circunstâncias de dependência em relação aos países do centro do capitalismo e que têm um tipo de cultura fortemente elitista. O caráter dual do formalismo implica que as normas sociais e legais são sempre adaptáveis à realidade e têm um caráter convencional. É um tipo de comportamento de sociedades que carecem de forma, porquanto sua cultura se alinhe a parâmetros de uma mentalidade colonizada. A não obediência às normas e sua adaptação à realidade no cotidiano dos órgãos administrativos do Estado é a tônica de sociedades prismáticas. O resultado é que projetos de desenvolvimento, que implicam mudança dos padrões normativos da sociedade, esbarram em convenções previamente fixadas e em um comportamento ora irônico, ora histriônico das elites. A conduta política das elites ou se baseia em uma ironia de fundo ou em uma reação moralista pouco organizada, fazendo com que o formalismo implique em um conservadorismo de base que impede a mudança dos valores da cultura social (Ramos, 1966, p.341).

Em sociedades que convivem com o 
formalismo, normalmente os indivíduos têm consciência das normas existentes, contudo sua ação concreta ocorre em contextos que procuram adaptar as normas existentes às necessidades reais. Esta discrepância entre normas e comportamento implica o fato de que o processo de desenvolvimento ocorra em torno de um processo de acomodação. O desenvolvimento econômico e a modernização administrativa do Estado não implicam uma mudança estrutural profunda, mas apenas um processo de acomodação da sociedade ao estilo de vida moderno. Como ressalta Guerreiro Ramos, o formalismo não impede o desenvolvimento econômico. Muitas vezes faz com que ele se torne necessário. Mas as mudanças sociais nunca ocorrem de modo a serem inclusivas e profundas. Respeitam apenas a um processo de acomodação e complementaridade, os quais não permitem uma institucionalização efetiva de normas modernas e um processo autêntico de transformação. Em sociedades prismáticas, a mudança social ocorre, mas sempre pautada por uma elite que reinventa seus valores tradicionais.

No caso brasileiro, segundo Guerreiro Ramos, o formalismo ocorre exatamente pela falta de forma à Nação. O processo de independência foi apenas um processo formal de ruptura com o estatuto colonial. Pelo fato de Nação não ter forma, isso fez com que ela tivesse que tomar emprestado a outras nações os seus valores, modos de vida, hábitos de consumo, padrões de trabalho, instituições políticas. Institucionalmente, a sociedade brasileira seria, em seu nascedouro, uma sociedade formalística. Na literatura, haveria um estilo formalístico, preocupado com a forma e não com a autenticidade de seu conteúdo. ${ }^{3}$ O mesmo se pode dizer da política. Seguindo as contribuições de Alberto Torres e Oliveira Vianna, a política brasileira seria pautada por um comportamento elitista que seguiria um "idealismo utópico" da organização institucional do

${ }^{3}$ Guerreiro Ramos apoia-se em Sílvio Romero para afirmar que a literatura brasileira teria um tom formalístico. Para Romero, a literatura brasileira seguiria padrões dogmáticos definidos em estilos adventícios determinados pela cultura francesa. A esse respeito, conferir Ramos (1966, p.352).
Estado. Este idealismo implica o fato de as instituições políticas distanciarem-se da cultura nacional, resultando, necessariamente, em um padrão apenas formal - e não efetivo - de cidadania e de direitos. Para Guerreiro Ramos, Visconde do Uruguay, Oliveira Vianna, Silvio Romero e Alberto Torres foram os primeiros a fazerem a crítica do formalismo brasileiro. Mas nenhum deles, de acordo com o autor, logrou atingir uma compreensão satisfatória do formalismo brasileiro. Apesar de Guerreiro citar autores do pensamento autoritário como importantes à crítica do formalismo brasileiro, ele ressalta que os corretivos propostos refletem uma compreensão parcial da natureza do fenômeno, ao acreditarem que o Estado, sobrepondo-se autoritariamente à sociedade, pudesse conduzir o Brasil ao caminho da modernidade (Ramos, 1966, p.361).

Para Guerreiro Ramos, o formalismo brasileiro implica um jeito como o genuíno processo para resolver dificuldades. O jeitinho é uma estratégia para contornar dificuldades a despeito da lei ou mesmo contra ela. É uma condição de sobrevivência do indivíduo em uma sociedade que carece de processos mais sólidos de institucionalização da lei. É também uma estratégia de preservação do corpo social, no qual as leis são textos fora de contextos e não respeitam a cultura nacional de fundo. O Brasil seria uma sociedade que transplanta leis advindas de experiências estrangeiras de forma acrítica, sem estabelecer a relevância delas para as necessidades reais do desenvolvimento. Importante frisar que, para Guerreiro Ramos, o jeitinho não é uma regra do caráter nacional brasileiro, equivalente a um traço de originalidade do brasileiro. Não é um tipo de comportamento herdado do patrimonialismo português. O jeitinho é a vigência do formalismo em um contexto de uma estrutura de poder altamente oligárquica e diferenciada (Ramos, 1966, p.381).

Nesse sentido, frente ao formalismo e ao jeitinho na cultura brasileira, não basta a importação de normas e leis definidas no estrangeiro. O resultado disso é constituir, na sociedade bra- 
sileira, uma devassa moral que pode resultar em formas autoritárias e mais oligarquizadas de poder. Importar soluções modernizantes sem o processo de redução sociológica implica a adoção de soluções hipercorretas, mas que geram reações conservadoras na base da sociedade. O político e o administrador devem adotar, frente ao formalismo, não a busca de soluções hipercorretas, mas uma concepção estratégica de desenvolvimento capaz de colocar o Brasil na rota da modernidade. Dessa forma, o formalismo não deve ser uma espécie de inimigo inconteste da sociedade, nem mesmo se devem transplantar ideias e normas que serviram ao desenvolvimento de países do centro do capitalismo. O formalismo brasileiro, ao ser concebido dentro de uma concepção estratégica de desenvolvimento, com base no processo de redução sociológica, deve servir à modernização (Ramos, 1966, p.387). O fundamental é romper com uma perspectiva elitista e colonizada, constituindo estratégias próprias de desenvolvimento que alicercem um caminho próprio para a modernização, sem as tautologias designadas por uma concepção que queira estabelecer os pré-requisitos do desenvolvimento.

Seguindo a afirmação de Euclides da $\mathrm{Cu}-$ nha de que o Brasil seria " $[. .$.$] o único caso histó-$ rico de uma nacionalidade feita por uma teoria política" (Cunha, 1999, p.341), Guerreiro Ramos afirma que a origem do formalismo está no processo de construção nacional. Segundo ele:

Os três poderes, nas velhas nações, foram primeiramente uma realidade, costumes coletivamente consagrados e, depois, uma teoria formal e sistemática, elaborada e discutida por autores. No Brasil, por força da particularidade da sua formação histórica, observa-se o inverso desse processo. Não caminhamos do costume para a teoria; do vivido concreta e materialmente para o esquema formal. É o inverso que se dá; caminhamos, até agora, no tocante à construção nacional (nation building), do teórico para o consuetudinário, do formal para o concretamente vivido. O formalismo é, nas circunstâncias típicas e regulares que caracterizam a história do Brasil, uma estratégia de construção nacional (nation building). (Ramos, 1966, p.389)

Romper com as interpretações tautológicas do formalismo brasileiro significa partir da pre- missa de que qualquer estratégia de desenvolvimento deve encará-lo como elemento central para a sua consecução. Uma vez que o formalismo é o elemento definidor da Nação, já que as regras sempre tiveram um caráter exógeno, derivado de uma mentalidade colonial, qualquer projeto de mudança social no Brasil deve adotá-lo como estratégia para o desenvolvimento. Se o desenvolvimento, respeitando uma mentalidade póscolonial, deve estar alicerçado no plano dos valores e percepções definido pela cultura, o formalismo brasileiro deve ser um elemento central para a constituição de uma estratégia de desenvolvimento sem a presença de soluções hipercorretas.

Para Guerreiro Ramos é essa característica formal da sociedade brasileira que permite a sua articulação, como sociedade periférica, com o mundo. A sociedade brasileira, em função do formalismo, mostra-se uma sociedade adaptável à mudança. No caso da administração pública, o formalismo permite certa maleabilidade das instituições em relação à sociedade. Ademais, o excedente de pessoas diplomadas pode ser incorporado no Estado, de modo que o formalismo contribua para a mobilidade social ascendente. A mobilidade ascendente de negros, por exemplo, foi fortemente influenciada pela presença deles no serviço público brasileiro (Ramos, 1960). O formalismo, segundo Guerreiro Ramos, “[...] atesta que ela está em movimento histórico, ascendente, positivo; que está deixando de ser o que era” (Ramos, 1966, p.395).

$\mathrm{O}$ formalismo é um fenômeno inerente à realidade social brasileira e é elemento imprescindível de ser considerado em qualquer estratégia de desenvolvimento, uma vez que a base do processo de construção nacional se deu a partir de seu alcance. Portanto, ele é, no Brasil, um fenômeno regular e normal, que existe em função de uma cultura política mais sólida. O formalismo é o momento de uma transição, que respeita um processo histórico em que a institucionalização de normas deve obedecer a um processo regular de gradativa institucionalização na cultura naci- 
onal. Guerreiro Ramos era, antes de qualquer coisa, um otimista em relação ao Brasil. Para ele:

O desenvolvimento, no Brasil, enquanto persistir a dualidade, jamais implicará, em cada fase, a substituição integral do velho pelo novo, mas, antes, a cooptação do velho pelo novo, dos elementos arcaicos e retardatários pelos elementos modernos e atuais. (1966, p.417).

Sendo assim, o formalismo é uma estratégia de mudança social, imposta pelo caráter dual da formação histórica brasileira e pelo modo como o Brasil se articula com o mundo. Reconhecido isso, é possível, segundo Guerreiro Ramos, superar a mentalidade colonial, para que a sociologia tenha o papel fundamental de compreender e trabalhar com o caráter existencial da cultura brasileira, a qual, de acordo com ele, ainda é fenômeno obscuro e passível de interpretação. Buscar as bases existenciais da sociedade brasileira, por meio da redução sociológica, é reconhecer que a rota para o desenvolvimento deve estar alicerçada no conjunto de problemas práticos que o fato nacional brasileiro implica.

\section{CONSIDERAÇÕES FINAIS}

Este texto tratou das bases epistemológicas fundamentais do pensamento social de Alberto Guerreiro Ramos. Mostramos que esse autor, ao estabelecer o método da redução sociológica, proporcionou a consolidação de uma concepção própria de desenvolvimento para o Brasil, a qual está preocupada, fundamentalmente, com as bases interpretativas da cultura, de forma a consolidar uma via própria para a modernização.

Esse movimento de discussão metodológica do fazer sociológico no Brasil e a sua importância para a interpretação de nossas condições existenciais proporcionaram a consolidação de uma perspectiva de desenvolvimento alicerçada em um imaginário pós-colonial. Importante observar que esse imaginário pós-colonial é publicamente informado e orientado pelas bases interpretativas abertas pelo conhecimento autên- tico da cultura brasileira. Não se propala, então, uma fórmula universal para o desenvolvimento, mas uma perspectiva estratégica e cientificamente informada. A sociologia, nesse sentido, tem papel fundamental, à medida que não seja concebida em um marco institucional universal, mas que seja capaz de arregaçar as mangas em prol de uma cultura em formação, que busca o seu lugar no mundo.

No atual contexto de revisão e revisitação das estratégias de desenvolvimento, deflagradas no atual estágio da sociedade brasileira, é impossível não perceber as possibilidades que tanto o pensamento de Guerreiro Ramos quanto o pensamento pós-colonial podem exercer na configuração de um caminho próprio. Isso significa que há possibilidade de que os projetos sejam revistos e não se cometam os mesmos erros do passado. Nesse sentido, buscar as bases existenciais da cultura brasileira pode ser um caminho aberto à imaginação, com o condão de refletir e deixar consolidar a própria identidade nacional do Brasil. A janela de oportunidade ora aberta exige medidas de conhecimento. Nesse caso, a redução sociológica pode ser um caminho, dentre vários apresentados à sociedade brasileira.

\section{REFERÊNCIAS}

CUNHA, Euclides da. À margem da história. São Paulo: Martins Fontes, 1999.

FERNANDES, Florestan. A sociologia no Brasil. Petrópolis: Vozes, 1977.

FREYRE, Gilberto. Casa grande e senzala. In: SANTIAGO, Silviano (Org.) Intérpretes do Brasil. Rio de Janeiro: Nova Aguilar, 2000. v.2.

MAIO, Marcos Chor. Uma polêmica esquecida: Costa Pinto, Guerreiro Ramos e o tema das relações sociais. Dados: revista de Ciências Sociais, Rio de Janeiro, v.40, n.1, 1997.

OLIVEIRA, Lúcia Lippi de. A sociologia do Guerreiro. Rio de Janeiro: Ed. UFRJ, 1995.

RAMOS, Alberto Guerreiro. A redução sociológica. Rio de Janeiro: Ed. UFRJ, 1996.

. Administração e estratégia do desenvolvimento. Rio de Janeiro: Fundação Getúlio Vargas, 1966. 

Saga, 1960 .

O problema nacional brasileiro. Rio de Janeiro:

Condições sociais do poder nacional. Rio de Janeiro: MEC; Instituto Superior de Estudos Brasileiros, 1957.

O negro no Brasil e um exame de consciência. In: Relações de raça no Brasil. Rio de Janeiro: Edições Quilombo, 1950.

RAMOS, Arthur. O negro brasileiro. Rio de Janeiro: Graphia, 2002.

SANTOS, Boaventura de Souza. Crítica da razão indolente. São Paulo: Cortez, 2003.
SCHWARTZMAN, Simon. Painel sobre a contribuição de Guerreiro Ramos para a sociologia brasileira. Revista de Administração Pública, Rio de Janeiro, v.17, n.2, 1983.

SOUZA, Márcio Ferreira de. Guerreiro Ramos e o desenvolvimento nacional: a construção de um projeto para a nação. Belo Horizonte: Argumentvm, 2009.

SPIVAK, Gayatri C. Can the Subaltern Speak? In: WILLIAMS Patrick; CHRISMAN, Laura (Ed.) Colonial discourse and Post-Colonial Theory: a reader. New York: Columbia University Press, 1994. 


\section{GUERREIRO RAMOS, THE SOCIOLOGICAL REDUCTION AND THE POST COLONIAL IMAGINATION}

\author{
Fernando de Barros Filgueiras
}

The recent improvement of Latin-American sociology moves towards reinforcing and giving value to its own scientific production. This enables the consolidation of the self interpretation of its social reality, capable of promoting the development of several potentialities in Latin-American societies. The objective of this text is to recover the practical and epistemological positions of Alberto Guerreiro Ramos published in different media and recognized as a "sociological reduction". Based on Guerreiro Ramos' standpoints presented in the 2nd Latin-American Conference in Sociology, this paper aims at relating the terms of sociological reduction to the postcolonialist imagination, observing methodological proximities and distances from the craft of sociology and the innovations provided by the author, bearing in mind the sociological reduction.

KEY WORDS: sociological theory, Brazilian social thought, social sciences epistemology, nationalism, postcolonialism

\section{GUERREIRO RAMOS, LA RÉDUCTION SOCIOLOGIQUE ET L'IMAGINAIRE POST-COLO- NIAL}

\author{
Fernando de Barros Filgueiras
}

Le perfectionnement récent de la sociologie latino-américaine se veut de renforcer et de valoriser une production scientifique propre. Ceci permet la consolidation d'une auto-interprétation de sa réalité sociale capable de promouvoir le développement des diverses potentialités des sociétés latino-américaines. L'objectif de cette étude est de reprendre les opinions pratiques et épistémologiques d'Alberto Guerreiro Ramos publiées dans différents milieux et connues en tant que "réduction sociologique". Partant des idées de Guerreiro Ramos présentées lors du IIe Congrès Latino-Américain de Sociologie, nous voulons faire le lien entre les termes de la réduction sociologique et l'imaginaire post-colonialiste, à partir de l'observation des rapprochements et des éloignements méthodologiques du travail de la sociologie ainsi que les innovations apportées par l'auteur avec ce concept de réduction sociologique.

Mотs-CLÉs: théorie sociologique, pensée sociale brésilienne, épistémologie des sciences sociales, nationalisme, post colonialisme.

Fernando de Barros Filgueiras - Doutor em Ciência Política. Professor adjunto da Universidade Federal de Minas Gerais (UFMG), no Departamento de Ciência Política (DCP), onde também ocupa a posição de chefe do Departamento. Tem experiência na área de Ciência Política, com ênfase em teoria política, políticas públicas e comportamento político, atuando principalmente nos seguintes temas: teoria política normativa, Estado e governo, teoria democrática, direito e democracia, corrupção e bom governo. É pesquisador e coordenador do Centro de Referência do Interesse Público da UFMG. Autor de "Corrupção, democracia e legitimidade", Editora UFMG, 2008. 